\title{
Lipids and Lipoproteins in Venezuelan and American Schoolchildren: Within and Cross-Cultural Comparisons
}

\author{
SOAIRA MENDOZA, GRACIELA CONTRERAS, EMILIO INEICHEN, MARIA FERNANDEZ, \\ H. NUCETE, J. A. MORRISON, P. S. GARTSIDE, AND C. J. GLUECK ${ }^{(19)}$
}

Pathophysiology Department, School of Medicine, University of Los Andes; Hormone Laboratory, University Hospital, Merida, Venezuela; and Lipid Research Clinic and General Clinical Research Center, University of Cincinnati, College of Medicine, Cincinnati, Ohio, USA

Summary

This study was designed to focus upon within-culture difierences in plasma lipids and lipoproteins in Venezuelan schoolchildren having different socioeconomic and nutritional backgrounds and also to provide cross-cultural comparisons of lipids, lipoproteins, and anthropometric measurements between Venezuelan and American schoolchildren. The study was carried out in 1298 schoolchildren, ages 7 to 12 years, 428 in private and 870 in public schools in Merida, Venezuela, with comparison to 472 public schoolchildren in the (Cincinnati, OH) Princeton School District. Within Venezuelan schools, private schoolchildren were heavier, taller, had marginally higher Quetelet indices, and had considerably higher fasting plasma cholesterol, plasma high-density lipoprotein (C-HDL), and plasma low-density lipoprotein (C-LDL) levels. These lipid-lipoprotein differences were highly significant after adjusting (by covariance analysis) for Quetelet index, sex, and age. Children from private Venezuelan schools ingested more total calories, more protein, more fat, and more carbohydrate. When the diet compositions were calculated as percentage of total calories, the private schoolchildren ingested nearly twice as many calories as fat and a somewhat lower proportion of calories as carbohydrate, with a comparable proportion as protein, when compared to the public Venezuelan schoolchildren. Male-female comparisons within Venezuelan schools revealed patterns of sexrelated lipoprotein differences which were qualitatively similar to those in Princeton schoolchildren. Thus, 7- to 12-year-old females had higher total plasma cholesterol and triglyceride, lower CHDL, and higher C-LDL. Within sex, cross-cultural comparisons of lipids, lipoproteins, and Quetelet indices revealed two major differences. Venezuelan children had significantly higher fasting plasma triglyceride and lower C-HDL levels, differences not attributable to systematic differences in measures of ponderosity, because Quetelet indices in Venezuelan and Cincinnati schoolchildren did not differ appreciably. In regard to total and lowdensity lipoprotein cholesterol, Venezuelan and Princeton public schoolchildren were remarkably comparable, although Venezuelan private schoolchildren had somewhat higher plasma cholesterol and C-LDL levels than did Princeton public schoolchildren. We speculate that increasing "westernization" and "urbanization" of Venezuelan society is associated with convergence of Venezuelan and American pediatric plasma lipid and lipoprotein levels. Maintenance of comparable total plasma cholesterol and C-LDL levels with lower C-HDL into adulthood in Venezuela would, in fact, suggest augmented risks for coronary heart disease for Venezuela within this lipid-lipoprotein frame of reference.

\section{Speculation}

We speculate that increasing "westernization" and "urbanization" of Venezuelan society is associated with convergence of
Venezuelan and American pediatric plasma lipid and lipoprotein levels. Maintenance of comparable total plasma cholesterol and plasma low-density lipoprotein levels, with lower plasma highdensity lipoprotein levels into adulthood in Venezuela would, in fact, suggest augmented risk for coronary heart disease in Venezuelans, within this lipid-lipoprotein frame of reference.

Previous studies on Guatemalan children (7), American Indians (16), and Tarahumara Indians from Mexico (4) have revealed that in rural agricultural environments, the mean plasma cholesterol level in children is considerably below levels in urban or suburban American children. However, a recent study of 6- to 15-year-old schoolchildren in Caracas, Venezuela, reported mean serum cholesterol of $176 \mathrm{mg} / \mathrm{dl}$ in boys and $175 \mathrm{mg} / \mathrm{dl}$ in girls (15), higher than mean levels of 160 and $161 \mathrm{mg} / \mathrm{dl}$ in 6- to 11 -year-old boys and girls in the suburban (Cincinnati, $\mathrm{OH}$ ) Princeton School study group (14). The mean plasma triglyceride level in Caracas boys, ages 6- to 10 , was $70 \mathrm{mg} / \mathrm{dl}$, and in girls, it was $53 \mathrm{mg} / \mathrm{dl}$ (15), with Princeton 6- to 10-year-old boys and girls having mean triglyceride levels of 57 and $62 \mathrm{mg} / \mathrm{dl}$, respectively (14).

The current report focuses upon within-culture differences in plasma lipids and lipoproteins in Venezuelan children having different socioeconomic and nutritional backgrounds and also provides cross-cultural comparisons of lipids and lipoproteins between Venezuelan and American schoolchildren.

\section{MATERIALS AND METHODS}

\section{VENEZUELAN SCHOOL CHILDREN; ETHNIC AND DEMOGRAPHIC} CHARACTERISTICS

This study was carried out in 1298 schoolchildren, ages 7 to 12 , 428 in private schools and 870 in public schools in Merida, Venezuela, with comparison to 472 public school children ages 7 to 12 in the (Cincinnati, $\mathrm{OH}$ ) Princeton School district (13).

All of the children, ages 7 to 12 at the time of the study, were attending either private or public schools in Merida, Venezuela. To encompass socioeconomic groups broadly, we studied from nine public and five private schools. The initial contact was made by talking with the children and their teachers, followed by obtaining written consent for the study. Detailed instructions were given to the students to abstain from all food and drink except water for $12 \mathrm{hr}$ prior to blood sampling. Fasting blood sampling was carried out between 7 and 9 A.M., after which the children were provided with breakfast. Prior to sampling, weight $(\mathrm{kg})$ and height $(\mathrm{cm})$ were recorded.

The private and the public schoolchildren were primarily of Mestizo ethnic origin. The majority of children in the private schools came from families of middle socioeconomic class with high levels of parental education. Conversely, the majority of 
children from the public schools came from parents of low socioeconomic class with low to middle levels of education.

\section{VENEZUELAN NUTRITIONAL PATTERNS}

A one-day diet recall was taken by a nutritionist from children and their mothers, including documentation of food type. Detailed information about the midday meals (served at the schools) was obtained to provide increased accuracy as to food components which made up the lunch meal. Using energy and nutrient tables for Venezuelan populations (8), a semiquantitative estimation of group nutritional patterns was made. Data were available for total calorie, protein, fat, and carbohydrate intake, but not for cholesterol intake.

\section{VENEZUELAN SUBJECT EXCLUSIONS}

Diabetic children and children with any other chronic diseases were excluded. Children taking any lipid lowering drugs, PO contraceptives, or hypotensive drugs were also excluded. These exclusions followed the protocol of the Lipid Research Clinic's study (14) and were identical to those used for the Princeton public school children included in this report $(11,13,14)$. The final study group members were healthy, normal children without any chronic diseases and taking no medications.

\section{PRINCETON SCHOOL CHILDREN}

The 472 Princeton schoolchildren attended public schools in suburban Cincinnati, $\mathrm{OH}$. As previously described $(13,14)$, they were primarily middle-class, $75 \%$ white, $25 \%$ black, and represented a random recall from all schoolchildren in the Princeton school district.

\section{ANALYTICAL TECHNIQUES; LIPIDS-LIPOPROTEINS, ANTHROPOMETRIC MEASUREMENTS}

In the Venezuelan children, plasma total cholesterol was quantitated by the method of Abell et al. (1) and plasma triglyceride by the (Fluorimetric) method of Kessler and Lederer (9). Plasma high-density lipoprotein cholesterol (C-HDL) was measured by the heparin-manganese precipitation method of Burstein and Samaille (2), and plasma low-density lipoprotein cholesterol levels (C-LDL) were calculated by the method of Friedewald et al. (5).

Plasma cholesterol, triglyceride, C-HDL, and C-LDL in the Princeton schoolchildren were quantitated by methods summarized in the Lipids Clinics Laboratory Manual (10), a LiebermanBurchard method for cholesterol, a modified fluorimetric method for triglycerides, and a heparin-Mn ${ }^{2+}$ precipitation for C-LDL. Because the Lipid Research Clinics method (10) for cholesterol is calibrated back to the method of Abell et al. (1) and because the triglyceride and $\mathrm{C}-\mathrm{HDL}$ methodologies were identical in the Cincinnati and Venezuelan Laboratories, the lipid-lipoprotein data should be generally comparable without specific laboratory bias.

The comparability of lipid and lipoprotein measurements in the Cincinnati and Venezuelan laboratories was assessed further by a double-blinded analysis of duplicate aliquots of fasting plasma from 50 randomly selected subjects. Mean ( \pm S.D.) cholesterol in these 50 plasma samples was $190 \pm 50 \mathrm{mg} / \mathrm{dl}$ in the Venezuelan laboratory and $186 \pm 46 \mathrm{mg} / \mathrm{dl}$ in Cincinnati, $P>0.1$ by $t$ test. Mean ( \pm S.D.) C-HDL levels in the 50 samples were $41 \pm 13$ and $38 \pm 10 \mathrm{mg} / \mathrm{dl}$ in the Venezuelan and Cincinnati laboratories, respectively $(P>0.1)$; mean ( \pm S.E.) triglyceride levels were 193 \pm 20 and $171 \pm 25 \mathrm{mg} / \mathrm{dl}$ in the Venezuelan and Cincinnati laboratories, respectively $(P>0.1)$. The comparability of measurements of total plasma cholesterol, C-HDL, and triglyceride in the aliquots of the 50 samples was further assessed by two-way analysis of variance (17). Plasma cholesterol and C-HDL determinations in the two laboratories in duplicate aliquots did not differ significantly $(F=3.8 ; \mathrm{df}=1,48 ; P>0.1),(F=0.4 ; \mathrm{df}=$ 1,$47 ; P>0.1$ ); triglyceride determinations differed marginally ( $F$ $=4.03 ; \mathrm{df}=1,49 ; P>0.1,>0.05$ ). Thus, although not providing identical values on duplicate aliquots of 50 samples, there were no significant between-laboratory differences for cholesterol, C-HDL, or triglyceride, although triglyceride levels in Venezuelan duplicates were marginally higher than in the Cincinnati laboratory.

In the Cincininati laboratory, the interday coefficients of variation for plasma cholesterol levels in pools containing 158 and 281 $\mathrm{mg} / \mathrm{dl}$ were $2.0 \%$ and $1.2 \%$, respectively (14), and those for plasma triglycerides in pools containing 66 and $153 \mathrm{mg} / \mathrm{dl}$ were 2.3 and $1.7 \%$, respectively. In the Venezuela laboratory, the interday coefficients of variation for plasma cholesterol levels in pools containing 158 and $250 \mathrm{mg} / \mathrm{dl}$ were 4.0 and $2.1 \%$, respectively, and those for plasma triglyceride in pools containing 96 and $254 \mathrm{mg} / \mathrm{dl}$ were 3.6 and $1.1 \%$, respectively.

Heights and weights were measured in both Venezuela and Cincinnati in an identical fashion following the standardized collaborative LRC protocol (11). Standing height was measured once in centimeters to the nearest $0.5 \mathrm{~cm}$ without shoes, the back square against the wall tape, eyes looking straight ahead, with a set square resting on the scalp and against the wall (11). The subject's weight was measured in kilograms to the nearest 0.1 kilogram in ordinary street clothes without heavy outer garments such as coats and sweaters. The scales were calibrated to zero prior to the beginning of each day's screening. These identical methods for measurement of height and weight were followed to provide assurance in cross-cultural comparison free of methodological bias.

\section{STATISTICAL METHODS}

Correlation matrices were calculated as per Snedecor and Cochran (17). To assess differences between Venezuelan children for lipid, lipoprotein, and anthropometric measures, covariance analysis was used with the lipid, lipoprotein, and anthropometric measurements as the dependent variables and covariance adjustment for explanatory variables, school, sex, school-sex interaction, age, and Quetelet Index (weight/height ${ }^{2}$ ) (17).

\section{RESULTS}

\section{LIPID AND LIPOPROTEIN DISTRIBUTIONS IN VENEZUELAN} CHILDREN

Table 1 summarizes the mean ( \pm S.D.) Quetelet Index, plasma cholesterol, triglyceride, C-HDL and C-LDL by year of age for Venezuelan private and public school children. At each year of age, children from the private schools for the most part had higher total cholesterol, higher C-HDL, and higher C-LDL (Table 1). Within schools, female children generally had higher total cholesterol, uniformly had higher triglyceride, generally had lower levels of C-HDL and, at most ages, had higher levels of C-LDL (Table 1).

\section{COVARIANCE ANALYSIS OF LIPID AND LIPOPROTEIN LEVELS AND THEIR RELATIONSHIPS TO SCHOOL, AGE, SEX, AND QUETELET INDEX: VENEZUELAN SCHOOLCHILDREN}

As summarized in Table 2, covariance analysis was carried out with the dependent variables being cholesterol, triglyceride, CHDL, and C-LDL. Covariance adjustment was made for school, sex, school-sex interaction, age, and Quetelet index. Thus, after adjustment for confounding variables (school, sex, school-sex interaction, age, and Quetelet Index), plasma cholesterol differed significantly by school, being higher in the private school children, and by sex, being higher in females (Table 2). Although plasma triglyceride levels did not differ by school, they differed significantly by sex, being higher in females, significantly by Quetelet, being higher in more obese children, and rose significantly with age (Table 2). Plasma C-HDL levels differed significantly by school, being higher in private schoolchildren, differed significantly by sex, being higher in males, and differed significantly by Quetelet, being lower in the more obese children. Plasma C-LDL levels differed significantly by school, being higher in the children from private school and in females and being somewhat higher in children who were more obese (Table 2).

By covariance analysis, after adjustment for sex, age, and 


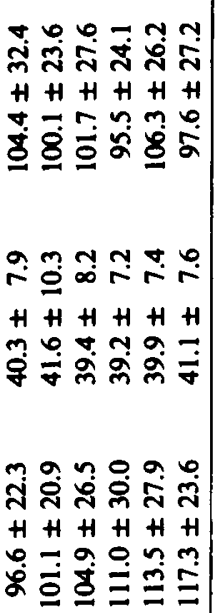

$\infty 0+r a \infty$

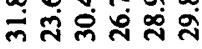
$\mathrm{H}+\mathrm{H}+\mathrm{H} H$ ลิ่ స్తి స్త్ర

象 $\mathrm{H}+\mathrm{H}+\mathrm{H}+\mathrm{H}$ - $a n-100$

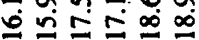

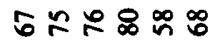

我

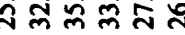
$\mathrm{H} H \mathrm{H} H \mathrm{H}$ $\forall m \backsim a n$ ริ으응응

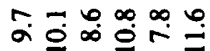
H H H H H H

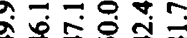

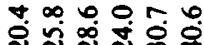
సิ స $\mathrm{H}+\mathrm{H}+\mathrm{H}+1+1$

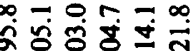

में $\mathrm{H}+\mathrm{H} H+\mathrm{H}$ $N=m m b \sigma$

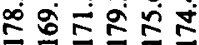

momran $+H+H+H+H$ $n \backsim \sim \backsim b m$ $0=0 \leq \infty a$

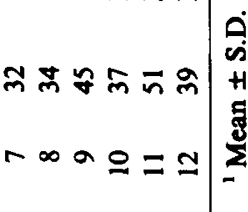

school-sex interaction, private schoolchildren were heavier $(F=$ 36; $P<0.0001)$, taller $(F=80 ; P<0.0001)$, and had a slightly higher Quetelet index $(F=4.5 ; P=0.05)$.

\section{CORRELATIONS BETWEEN AGE, QUETELET INDEX, LIPIDS AND LIPOPROTEINS IN VENEZUELAN CHILDREN}

Table 3 summarizes interrelationships for all 1298 Venezuelan schoolchildren of anthropometric, lipid, and lipoprotein measurements. Age was positively related to Quetelet index $(P<0.0001)$ and triglyceride levels $(P<0.0001)$. The Quetelet index was positively related to cholesterol $(P<0.05)$, C-LDL $(P<0.05)$, and to triglyceride $(P<0.0001)$, and significantly inversely related to C-HDL $(P<0.01)$. total plasma cholesterol was positively related to triglyceride $(P<0.0001)$, C-HDL $(P<0.0001)$, and CLDL $(P<0.0001)$. Triglyceride levels were inversely related to $C$ HDL $(P<0.0001)$ and positively related to C-LDL $(P<0.01)$.

\section{CROSS-SECTIONAL CHANGES IN PLASMA LIPIDS AND PROTEINS WITH AGE IN VENEZUELAN CHILDREN}

As summarized in Table 1 , with increasing age, the mean plasma cholesterol levels in both private and public schoolchildren were relatively stable between ages 7 to 11 . Conversely, with increasing age, the mean plasma triglyceride levels tended to rise, with the increments particularly marked between ages 10 and 12 (Table 1).

In the private school boys and girls, plasma C-HDL levels fell slightly at ages 11 and 12 , but there were no consistent patterns of changes in C-HDL in public schoolchildren. There was no consistent age-related pattern of change in C-LDL levels in any of the groups of Venezuelan schoolchildren. At least for the Venezuelan private schoolchildren, these findings were rather comparable to those in the Princeton School study (14), where plasma cholesterol levels also fell at ages 11 and 12, whereas plasma triglyceride levels rose. In the Princeton school children, mean CHDL also fell with increasing age, but the declension was not observed until ages 14 to 15 in males and 16 to 17 in females.

\section{NUTRITIONAL PATTERNS FOR VENEZUELAN CHILDREN}

Table 4 summarizes nutritional patterns for the Venezuelan children by school. Children from private school ingested more total calories, more protein, more fat, and more carbohydrate. When the diet compositions are calculated as percentage of total calories (Table 4), the private school children ingested nearly twice as many calories as fat and a somewhat lower proportion of calories from carbohydrate, with a comparable proportion as protein, when compared to the public school children.

\section{PERCENTILE DISTRIBUTION LIPIDS, LIPOPROTEINS, AND QUETELET INDICES: VENEZUELAN AND CINCINNATI CHILDREN}

In Table 5, the 5th, 10th, 50th, 90th, and 95th percentiles for all 1298 Venezuelan private and public school children, ages 7 to 12 , are summarized, and for comparison purposes, so are the percentile distributions for blacks and whites from the Princeton school child study (14). The selection of the 5th, 10th, 50th, 90th, and 95th percentile levels is arbitrary but allows the practitioner to place each individual into a percentile group roughly related to increased risk for coronary heart disease as an adult (total cholesterol, triglyceride, and C-LDL) or reduced risk (C-HDL).

As summarized in Table 5, the overall distributions for Venezuelan and American school children for plasma cholesterol and C-LDL were generally similar. However, at each point in the distribution, the Venezuelan children had higher triglyceride and lower C-HDL levels than did American children.

\section{COMPARISON OF LIPID AND LIPOPROTEIN LEVELS IN} VENEZUELAN AND CINCINNATI SCHOOLCHILDREN

Table 6 summarizes mean ( \pm S.D.) plasma cholesterol, triglyceride, C-HDL, C-LDL, and Quetelet index in Venezuelan private 
Table 2. Covariance analysis, lipids and, lipoproteins as dependent variables, covariance adjustment for school, sex, school-sex interaction, age, and quetelet index: all Venezuelan schoolchildren $(n=1298)$

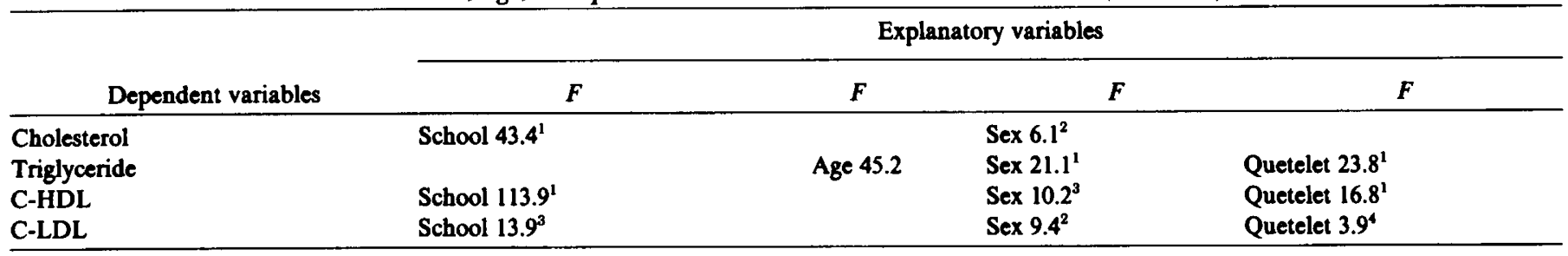

${ }^{1} P<0.0001$, for $F$ with 1 and 1292 df.

${ }^{2} P<0.01$, for $F$ with 1 and 1292 df.

${ }^{3} P<0.001$, for $F$ with 1 and $1292 \mathrm{df}$.

${ }^{4} P<0.05$, for $F$ with 1 and $1292 \mathrm{df}$.

Table 3. Correlation matrix, 1298 Venezuelan school children; age, quetelet index, plasma total cholesterol, triglyceride, C-HDL, $C-L D L$

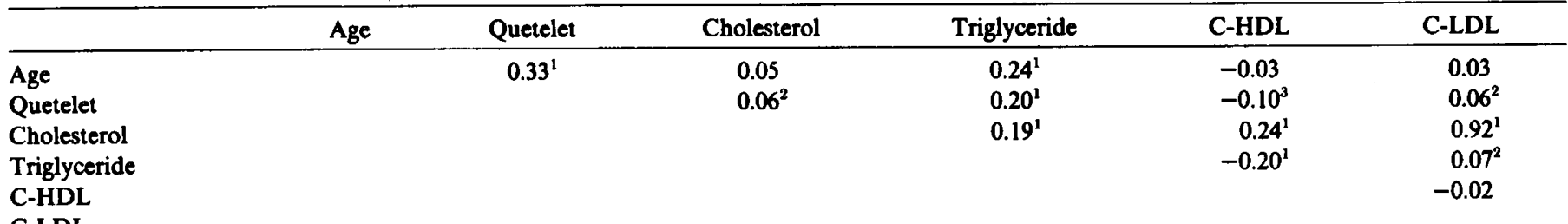

C-LDL

$$
\begin{aligned}
& { }^{1} P<0.0001 . \\
& { }^{2} P<.05 . \\
& { }^{3} P<0.01 .
\end{aligned}
$$

Table 4. Nutritional patterns for 870 public and 428 private Venezuelan school children

\begin{tabular}{lllll}
\hline & & g/day & Calories/day & \% of total calories \\
\hline Proteins & Public school & $43.9 \pm 5.6$ & $175.6 \pm 22.6$ & 15 \\
& Private school & $62.1 \pm 4.4^{1}$ & $248.5 \pm 17.6^{1}$ & 15 \\
Fats & Public school & $37.4 \pm 2.1$ & $336.9 \pm 18.5$ & 29 \\
& Private school & $76.9 \pm 3.9^{1}$ & $692.7 \pm 34.6^{1}$ & $42^{1}$ \\
Carbohydrates & Public School & $166.3 \pm 4.6$ & $665.2 \pm 18.4$ & 56 \\
& Private school & $174.9 \pm 3.8^{1}$ & $699.5 \pm 15.3^{1}$ & $43^{2}$ \\
Total calories & Public school & & $1177.8 \pm 35.3$ & $1640.7 \pm 47.7^{1}$ \\
\hline
\end{tabular}

$$
\begin{aligned}
& { }^{1} P<0.001 . \\
& { }^{2} P<0.01 .
\end{aligned}
$$

and public schoolchildren, and Cincinnati black and white public schoolchildren. The major, uniform differences between Venezuelan and Cincinnati schoolchildren included higher triglyceride and lower C-HDL levels in the Venezuelan children of both sexes. Venezuelan private school boys and girls had higher total plasma cholesterol than did Cincinnati white boys and girls and black girls, respectively. Venezuelan private school boys and girls also had higher C-LDL than did Cincinnati white boys and girls.

The lack of any significant difference between measurement of plasma cholesterol and C-HDL in duplicate aliquots in the Cincinnati and Venezuelan laboratories allows assurance that the cross-cultural differences were not due to systematic laboratory differences. Plasma triglyceride levels were marginally higher $(\boldsymbol{P}$ $<0.1$ and $>0.05$ ) in Venezuelan laboratory measurements when compared to Cincinnati, however, so that a small portion of the higher plasma triglycerides in Venezuelan children might be attributed to laboratory difference.

There was no significant Venezuelan-Cincinnati difference in Quetelet index using identical measurment techniques.

\section{BETWEEN SEX, WITHIN-CULTURE COMPARISONS OF LIPIDS AND LIPOPROTEINS}

The between-sex, within-culture patterns were very similar for both populations. Thus, girls had somewhat higher mean plasma cholesterol and triglyceride than did boys (Table 6). Moreover, girls had lower mean C-HDL and higher C-LDL than did boys (Table 6).

\section{DISCUSSION}

Within Venezuelan schools, private schoolchildren were heavier, taller, had marginally higher Quetelet indices, and had considerably higher fasting plasma cholesterol, C-HDL, and C-LDL levels. The lipid-lipoprotein differences were highly significant after adjusting (by covariance analysis) for Quetelet index, sex, and age. We speculate that a portion of the private-public school differences in cholesterol, C-HDL, and C-LDL are related to differences in nutritional patterns, with private schoolchildren ingesting more calories, a larger percentage of calories as fat, and a lower percentage of calories as carbohydrate. As was noted for the Tarahumara Indians (4), diets relatively low in fat (and cholesterol) and high in carbohydrate may be related to relatively low C-HDL levels, as observed in the public schoolchildren.

Male-female comparisons within Venezuelan schools revealed patterns of sex-related lipoprotein differences which were qualitatively similar to those in Princeton schoolchildren $(13,14)$. Thus, 7- to 12-year old females had higher total plasma cholesterol and triglyceride, lower C-HDL, and higher C-LDL. In Venezuelan private schoolchildren, the lowest C-HDL levels were found in 12 
Table 5. Percentile distributions (5th, 10th, 50th, 90th, and 95th) for plasma cholesterol, triglyceride, high-and low-density lipoprotein cholesterol (mg/dl), and Quetelet index: Venezuelan (Mestizo) and Princteon (black and white) schoolchildren, ages 7 to 12 years

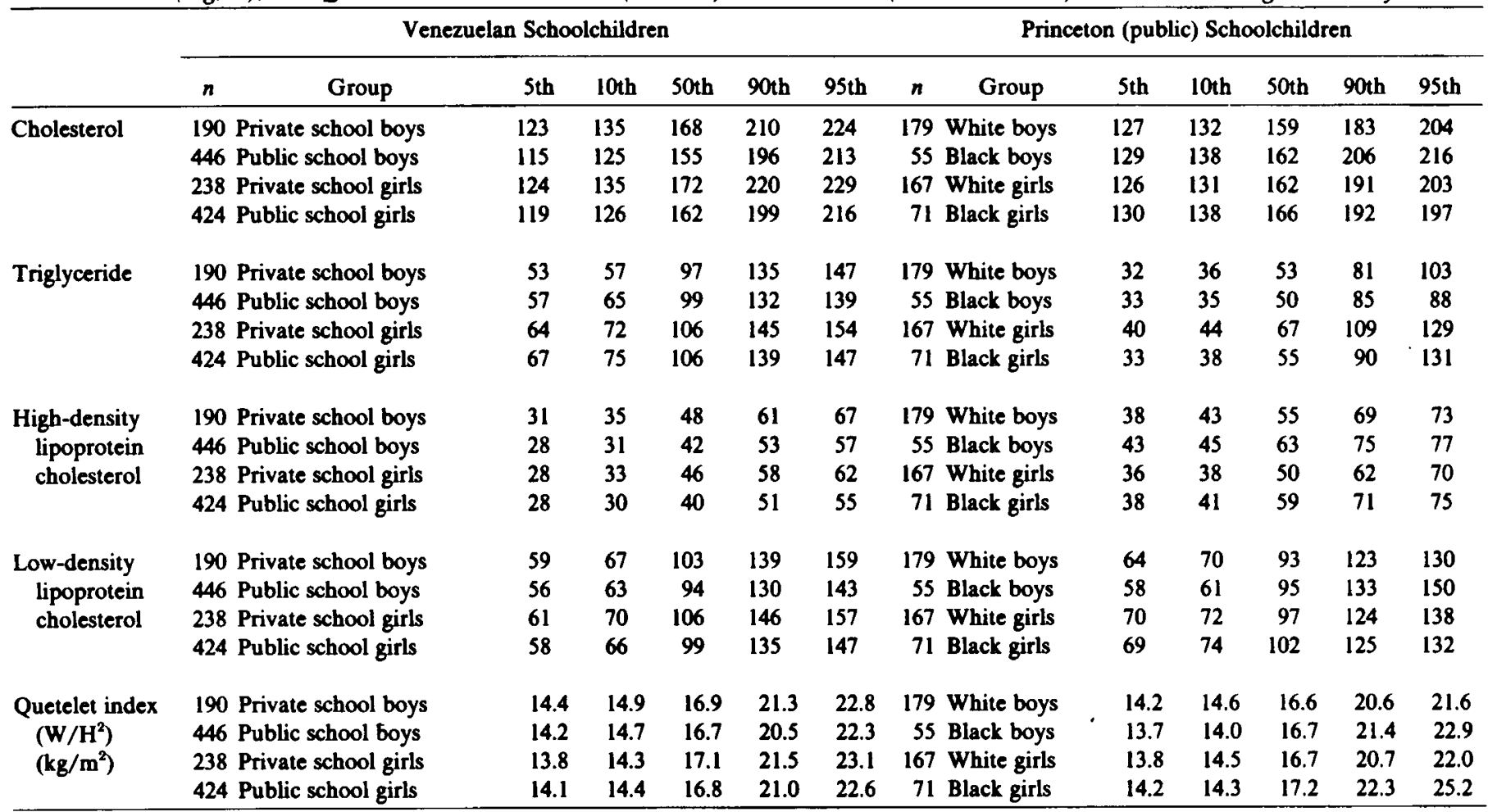

Table 6. Plasma cholesterol, triglyceride, high-and low-density lipoprotein cholesterol (mg/dl) and Quetelet index: comparison of Venezuelan (Mestizo) and Princeton (black and white) schoolchildren, ages 7 to 12 years

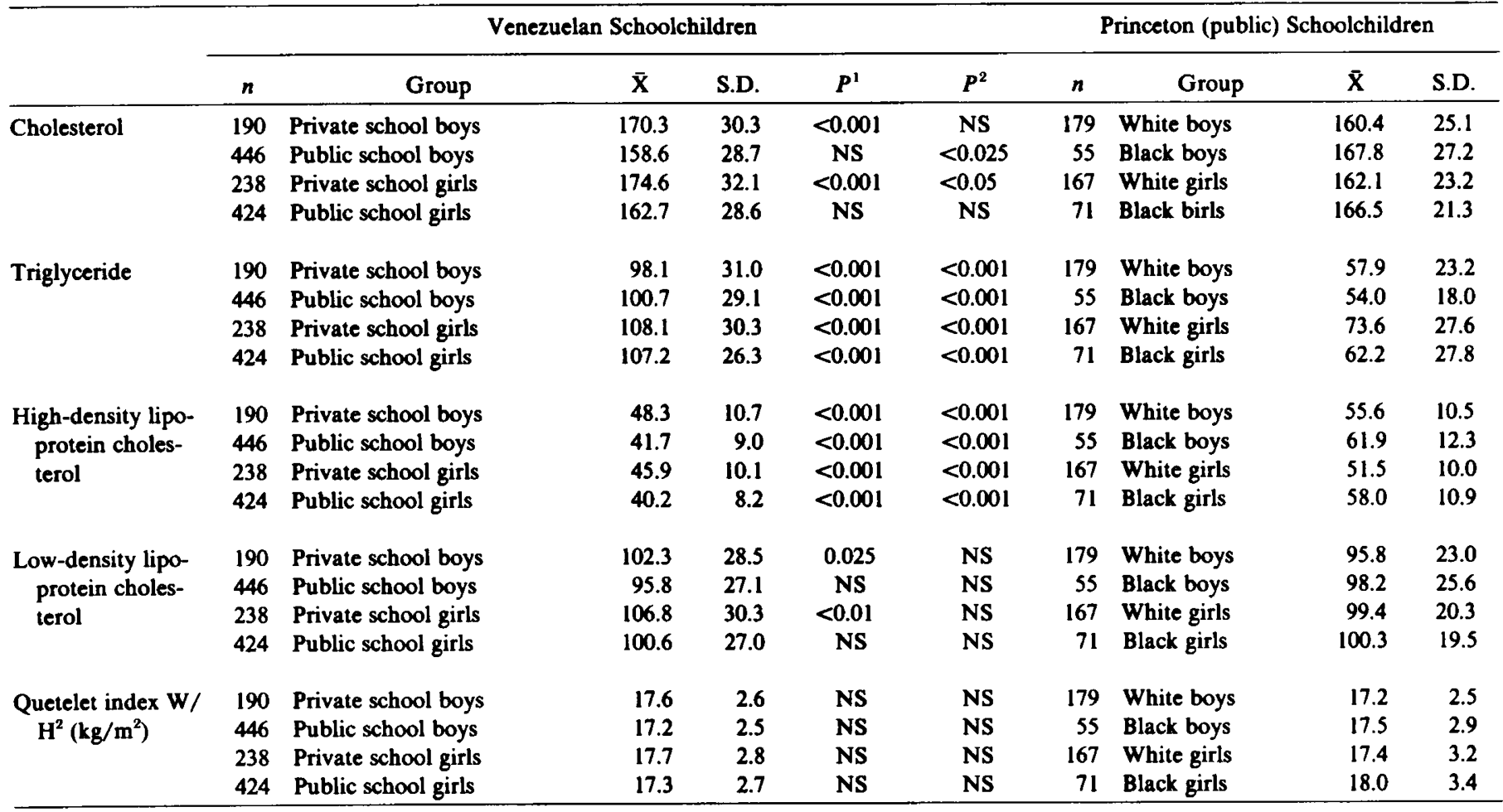

${ }^{1} P$ ', Venezuelan school children compared to Princeton white school children.

${ }^{2} P^{2}$, Venezuelan school children compared to Princeton black school children.

year olds, and the highest triglycerides were found at ages 11 and 12. In the Princeton schoolchildren (14), mean C-HDL also fell at the chronological initiation of pubertal changes, but the decline in C-HDL was not observed until age 14 to 15 in males and 16 to 17 in females. On-going studies in Venezuelan schoolchildren ages
13 to 18 will allow a more detailed cross-cultural comparison of changes in lipoproteins during puberty.

Within sex, cross-cultural comparisons of lipids, lipoproteins, and Quetelet indices revealed two major differences; Venezuelan children had significantly higher fasting plasma triglyceride and 
lower C-HDL levels. These cross-cultural differences were not attributable to systematic differences in measures of ponderosity because Quetelet indices in Venezuelan and Cincinnati schoolchildren did not differ appreciably. The triglyceride and C-HDL differences across cultures cannot be accounted for by differing laboratory methodology, subject selection, or sampling techniques (time of fasting) because these were similar or identical in the two populations studied. The etiology of this difference is unknown but is consistent with out findings of lower C-HDL and higher triglyceride levels in Venezuelan adults (from the Merida locale) as compared to Cincinnati adults (12).

In regard to total and LDL cholesterol, Venezuelan and Princeton public school children were remarkably comparable, whereas cholesterol and C-LDL levels were somewhat higher in Venezuelan private school children. These findings differ sharply from previous reports of much lower total and LDL cholesterol levels in rural, agricultural populations $(4,7,16)$ but are highly comparable to lipid levels recently reported for urban, Caracas Venezuelan children (15). We speculate that increasing "westernization" and "urbanization" of Venezuelan society is associated with convergence of Venezuelan and American pediatric plasma lipid and lipoprotein levels. Maintenance of comparable total plasma cholesterol and C-LDL levels, with lower C-HDL levels, into adulthood in Venezuela would in fact suggest augmented risk for coronary heart disease for Venezuelans within this lipid-lipoprotein frame of reference $(3,6)$.

The similarities in plasma cholesterol and triglyceride levels for these Merida, Venezuela children and those in Caracas (15) suggest that they probably have broad utility for the Venezuelan practitioner, although they cannot be directly generalized to all Venezuelan children. The plasma cholesterol and C-HDL levels in Venezuelan school children are comparable to those recently reported by our group for adults (12) using identical laboratory methodology. Thus, in adult Venezuelan females and males living at 1000 and 3500 meters altitude, mean C-HDL levels were 44 and 41 and 37 and $36 \mathrm{mg} / \mathrm{dl}$, respectively. Mean plasma cholesterol in adult Venezuelan females and males at 1000 and 3500 meters were 192 and 190 and 164 and $172 \mathrm{mg} / \mathrm{dl}$, respectively (12). These figures reflect the moderate age-related increases in plasma cholesterol and the relative age-related stability of C-HDL.

\section{CONCLUSION}

Venezuelan and American school children have relatively similar total and low-density lipoprotein cholesterol, whereas Venezuelan children have considerably higher levels of plasma triglyceride and lower levels of high-density lipoprotein cholesterol than American children. If these cross-cultural lipoprotein differences were maintained into adulthood, we speculate that coronary heart disease risk in Venezuela and America may converge or be increased in Venezuela.

\section{REFERENCES AND NOTES}

1. Abell, L., Levy, B., and Kendall, F.: A simplified method for estimation of total cholesterol in serum and demonstration of its specificity. J. Biol. Chem., 195: 357 (1952).

2. Burstein, M., and Samaille, J.: Sur un dosage rapide du cholesterol lie aux alpha et aux beta lipoproteins du serum. Clin. Chim. Acta, 5: 609 (1960).

3. Castelli, W. P., Doyle, J. T., Gordon, T., Hames, C. G., Hjortland, M. C., Hulley, S. B., Kagan, A., and Zukel, W. J.: HDL cholesterol and other lipids in coronary heart disease-cooperative lipoprotein phenotyping study. Circulation, 55: 767 (1977).

4. Connor, W. E., Cerqueira, M. T., Connor, R. W., Wallace, R. B., Malinow, M. R., and Casdorph, H. R.: The plasma lipids, lipoproteins and diet of the Tarahumara Indians of Mexico. Am. J. Clin. Nutr., 31: 1131 (1978).

5. Friedewald, W., Levy, R. I., and Fredrickson, D. S.: Estimation of the concentration of low density lipoprotein cholesterol in plasma without use of the preparative ultracentrifuge. Clin. Chem., 18: 499 (1972).

6. Glueck, C. J., Gartside, P., Fallat, R. W., Sieiski, J., and Steiner, P. M.: Longevity syndromes: familial hypobeta and familial hyperalphalipoproteinemia. J. Lab. Clin. Med., 88: 941 (1976).

7. Golubjatnikov, R., Paskey, T., and Inhorn, S. L.: Serum cholesterol levels of Mexican and Wisconsin school children. Am. J. Epidemiol., 96: 36 (1972).

8. Instituto Nacional de Nutricion (Venezuela). Consejo nacional de Investigationes cientificas y technologicas. Serie de cuadernos azules, Puplicacion \#38, Caracas, Venezuela (1976).

9. Kessler, G., and Lederer, H.: Fluorimetric measurement of triglycerides In: L. Skeggs: Automation in analytical chemistry. Technicon Symposia. Fr. p. 341 (Mediad, Inc., New York, 1977).

10. Lipid and lipoprotein analysis. Lipid Research Clinics Program, National Institutes of Health Publication \#75-678 U. S. Department of Health, Education, and Welfare. Vol. 1 (1974).

11. Lipid Research Clinics Program: Reference Manual for Lipid Research Clinics Program Prevalence Study. University of North Carolina, Chapel Hill: Central Patient Registry and Coordinating Center for Lipid Research Clinics, Department of Biostatistics (1974).

12. Mendoza, S., Nucete, H., Ineichen, E., Salazar, E., Zorpa, A., and Glueck, C. J.: Lipids and lipoproteins in subjects at 3,500 and 1,000 meters altitude. Arch. Environ Health, 34: 308 (1979).

13. Morrison, J. A., deGroot, I., Edwards, B. K., Kelly, K. A., Mellies, M. J., Khoury, P., and Glueck, C. J.: Lipids and lipoproteins in 927 schoolchildren ages 6-17 years. Pediatrics, 62: 990 (1978).

14. Morrison, J. A., deGroot, I., Edwards, B. K., Kelly, K. A., Rauh, J. L., Mellies, M. J., and Glueck, C. J.: Plasma cholesterol and triglyceride levels in 6775 schoolchildren, ages 6-17. Metabolism, 26: 1199 (1977).

15. Munoz, S. A., Munoz, H. O., Zanbrano, F., DeBleiberg, C. S., and Guemon, N.: Blood lipids in metropolitan Caracas schoolchildren: a preliminary report. Acta Cient. Venez., 28: 98 (1977).

16. Savage, P. J., Hamman, R. F., Bartha, G., Dippe, S. E., Miller, M., and Bennett, P. H.: Serum cholesterol levels in American (Pima) Indian children in adolescents. Pediatrics, 58: 274 (1976).

17. Snedecor, G. W., and Cochran, W. G.: Statistical Methods Ames, Iowa, 6th ed., p. 190, 490, Ed. 6 (Iowa State University Press, Ames, IA, 1967).

18. The authors thank Lic. Victoria de Villarroel for the nutritional patterns data, ULA statistical Department for helping us with the selection of samples, Comissionaduria de Salud del estado.Merida for helping us with the children's breakfast, and students and their professors for their cooperation.

19. Requests for reprints should be addressed to: Dr. Charles J. Glueck, General Clinical Research Centre, Room C2-3, Cincinnati General Hospital, 234 Goodman Street, Cincinnati, OH 45267 (USA).

20. This research was supported in part by Venezuelan Grant FA 27-78-COCHULA, Merida, by the Lipid Research Clinics Contract N01HV2-2914 L, and by the General Clinical Research Center Grant RR 00068-15.

21. Received for publication December 13, 1978.

22. Accepted for publication June 13, 1979. 